\title{
Postmodern Paradigms and Brand Management in the "Search" Economy
}

I.D. number: 1047
Word count: 6654

Ming Lim

School of Management

University of Leicester

Ken Edwards Building

University Road

Leicester LE1 7RH

Phone: +44 01162523999

Fax: +44 01162525515

E-mail:m.lim@le.ac.uk

\begin{abstract}
The dynamics of virtual branding remain poorly understood. This paper argues that even postmodern conceptualizations of the branding paradigm fail to take into account the 'search' economy and the surge in 'search engine marketing' (SEM) technologies. One of the key characteristics of this new economy is what Baudrillard calls the "constraint of signification," allowing search engines to manipulate temporal, spatial and brand-consumer constructs in unprecedented ways. This paper proposes four key concepts to explain this new challenge to current branding paradigms: thematic spatialization, temporal hierarchization, consumer promiscuity and the consumer-as-brand-creator. Finally, implications for marketers and researchers are discussed.
\end{abstract}

Keywords: brands, postmodern branding paradigms, search economy, search engine optimization, technology marketing.

Reference to this paper should be made as follows: Lim, M. (2008) 'Postmodern Paradigms and Brand Management in the 'Search' Economy', Int. J. Internet Marketing and Advertising, Vol. x, No. x, pp. xxx.

Biographical notes: Ming Lim is Lecturer in Critical Marketing and Management at the University of Leicester School of Management (ULSM). She teaches Branding and Communications and Principles of Marketing in the MSc programme. She is Chair of the Marketing Committee and a member of the Research Ethics committee and the Centre of Philosophy and Political Economy (CPPE). She also holds the position of Coordinator of the Academy of Marketing's Corporate Brand, Corporate Reputation and Identity SIG. Her research is in the areas of postmodernism, literary theory and marketing, branding, political marketing, business ethics and higher education marketing.

Acknowledgements: I wish to thank the two anonymous reviewers and the editors of this special issue for their helpful comments on an earlier draft of this paper. This paper was originally presented at the 


\section{Postmodern Paradigms and Brand Management in the "Search" Economy}

Purpose: To conceptualize a branding model for the 'search' economy based on postmodernist frameworks and a study of its unique characteristics.

Methodology/Approach: A review of some of the latest debates on postmodern and post-postmodern branding theories is used as a lens to draw out their limitations for conceptualizing the 'search' economy. The paper then discusses current developments in models of search engine marketing and optimization and typical ways in which firms and individuals use such models to challenge the dominance of conventional brands and branding techniques.

Findings: This paper identifies a conceptual gap between current branding theories and the developments of the economy of search. It analyses the limitations of current paradigms of branding to show that such theories cannot adequately address an entirely new generation of brands emerging from search technologies and the intermediaries associated with them.

\section{Research Implications:}

This paper will lead to more innovative and robust constructions of online branding as well as open the way to new critiques of current (postmodern and post-postmodern) theories of consumer behaviour and brand value concepts.

\section{Practical Implications:}

A valuable reminder to marketers and communications professionals that all planning in the future should include strategies for 'search' branding as well as measures to account for brand 'optimization' and 'spend' in this new economy.

\section{Value/Originality of Paper:}

Novel application of the postmodern and post-postmodern paradigm to 'search' marketing.

Type: Conceptual 


\section{Introduction}

The speed and scope of changes within the information and communications (ICT) domain have been extensively discussed in the social sciences, notably by sociologists, philosophers and anthropologists. Yet, their impact remains under-explored in the academic disciplines of marketing and advertising (Venkatesh et al., 1995). As researchers have noted, there is a lack of academic research on the implications of technological innovations for both marketing theory (Katz, 1991) and practice (Venkatesh et al., 1995; also see Dholakia and Rego, 1998; McLaughlin 1996; Kling, 1994). This gap is particularly surprising given the genuinely impressive gains made in the field of consumer research by authors who have used a postmodern framework (Holt, 2002) to identify the effects of the online economy upon postmodern notions of subjectivity, identity and consumption. In particular, the question of how the World Wide Web is transforming the consumption of brands remains underexplored (see Lindstrom, 2001).

This paper thus aim to draw out connections between postmodernist critiques of brands and a new generation of online consumers who are helping to change how brands position themselves in the digital environment. To focus the research, I examine these connections through the lens of one of the newest and most powerful Internet phenomena today, that of 'search' advertising or Search Engine Marketing (SEM). Branding through 'search' has now become the obsession of global firms and its research potential for marketing researchers cannot be underestimated. This new economy which now dominates cyberspace should help answer some of the questions posed above and which conventional 'critical' accounts of brand theory often fail to confront.

\section{Postmodernity and the Globalisation of 'Trust' and 'Identity'}

Ever since Giddens' (1990) argued that 'globalisation' must be placed firmly 'in the lexicon of the social sciences' (p. 52), a plethora of views about how technological advancements interact with, and even exceed, notions of postmodernity have emerged. Philosophical attempts to "order the disorderly" (Bauman, 1997, p.83) consequences of 'postmodernity' (Bauman 1997; Beck, 2006) have identified, among other themes, the 
blurring of the limits and boundaries of individual subjectivity in relation to the collective imagination, based on the incredulity about modern narratives of progress which sustained the modern (as opposed to the postmodern) imagination (Lyotard 1984: orig. 1979). Giddens agrees that what sociologists call 'postmodernity' appear to be signalled by a disappointment with "providential views of history (and) the dissolution of foundationalism" (p. 52), particularly in the West. The critique of self and identity is part of the legacy of this discourse, as well as the notion that cosmopolitanism evokes the globalization of risk and uncertainty (Beck, 2006).

One of Giddens's key insights into these processes I want to take up here is summed up in his discussion on reflexivity - it is not that postmodernity "overcomes modernity" (this simply makes no intellectual sense, to Giddens); rather, postmodernity is "modernity coming to understand itself' (p. 48). This reflexivity is not just the provenance of philosophers - it is now the lived experience of millions of people. One of its most compelling manifestations, according to Giddens, is the way it transforms our intimate relations with others and with self. Two concepts, in particular-trust and identity -- are relevant for how technology is framed by the postmodernist consumer.

Although Giddens does not, in this context, name technology (or a type of technological development) directly as a source for what he calls the "transformation of intimacy" (p.112), he identifies clearly the trends which are accelerated by current information and communications technologies used by consumers. That is, trust becomes something which, in postmodernity, we give to strangers rather than friends or kin. Identity becomes an outcome of such interactions which are multiplied many times over in our daily lives. Thus, the globalising effects of what he calls "abstract systems" are now combined with localised concerns which the individuals has and which are driven primarily by the search for self-fulfilment and identity (Lasch, 1977, 1985). In this sense, the individual must find his or her identity through systems which are profoundly disembedded in space and time. This space-time distanciation is a "lifting out" of relations from contextual conditions and placed or 'dis-placed' across "indefinite spans of time-space" (Giddens, 1990, p. 21). This conceptualization of time-space distanciation, it has been noted, provides a powerful model of the Internet and the "degree of temporal and spatial 
distancing" (Slevin, 2000, p. 69) it involves for everyone who interacts with it. How consumers exercise trust and perform their identity or identities on the Internet, therefore, becomes an intriguing question and it is to this question we now turn.

\section{Conceptualizations of the Postmodern Consumer}

Consumer theorists have examined the search for an authentic identity which can be easily transported across time-space barriers and endlessly reproduced for others' consumption (e.g. Ahuvia, 2005; Firat et al., 1995; Belk, 1988). This strand of consumer research argues for a notion of 'selves' which seek plenitude and fulfillment through possessions, a project which both absorbs and also disillusions consumers. Belk (1988), for instance, speaks of a 'core self' which extends itself through loved objects. Ahuvia (2005), on the other hand, argues that consumers have a meta-narrative which allow similar emotions - like 'brand love' - to be displayed across interpersonal as well as consumer contexts. In this sense, consumers' intense attachments to brands become part of identity-construction (Carroll and Ahuvia, 2002).

Another strand of consumer research focuses on the reflexivity which pervades postmodernist thinking about selfhood and subjectivity (Firat and Schultz, 1997; Firat and Venkatesh, 1995). The empirical work of Thompson and Troester, (2002), for example, shows clearly how postmodern consumers who see themselves as natural health advocates display extremely skeptical attitudes, in this case, of conventional paradigms of health and beauty. According to the authors, "this diffuse cultural movement has challenged modernism's dominant, utopian vision of science and technology ....and provides one of the major historical conditions for the emergence of postmodernity" ( $p$. 566). The question of choice for postmodern consumers, therefore, is tied to a relativism which may be construed as a backlash against dogmatic moralism.

The 'critical turn' in brand theory (see Holt, 2002; Murray and Ozanne, 1991; Firat and Venkatesh, 1995) is marked precisely by a distinct sense of anger (even revulsion) against the global branding economy, on the one hand, and a rousing call to consumers to fight against the greedy machinations of marketers, advertisers and 'brand engineers,' on the other, 'The People versus The Corporate Cool Machine' (Lasn 2000, p. xvi). 
According to this influential version of the branding paradigm, the consumer is the participant in a counter-culture against the tyranny of brands and their tactics.

As Holt (2000) observes, this movement may be traced back to earlier critiques of mass culture, such as that put forward by Adorno and Horkheimer (1944). According to them, the culture industry works by engineering or forcing a system of differences upon commodities which in themselves constitute, in fact, an undifferentiated mass. This system of difference is channeled aggressively through brands (Holt 2000) which succeeded both in segmenting the consumer base as well as in flattening consumer desires and hence their identities. Marketers have thus become, in our time, cultural engineers endowed with insidious and troubling powers to influence consumers' aspirations and desires. For marketing theorists, this tendency must be challenged Ozanne and Murray (1995), for instance, argue that consumers need to be 'emancipated' from the grip of these codes and find ways of signaling their dissatisfaction with such manipulation. Firat and Venkatesh (1995), in a similar vein, offer a liberatory account of the postmodern consumer as the force which is steadily eroding the power of marketers' dominance. In their view, marketing is a historically-situated force and may well be coming to the end of its reign over the consumer. Holt (2000) takes on both sets of arguments and offers an alternative critique of how brands function in our time. Where marketing theory has tended to theorize similarities between marketing and consumers and is therefore obliged to use words and phrases like 'backlash' or 'anti-branding movement' to explain away dissonances between marketers and consumers -- Holt sees contradictions. Instead of seeing the consumer as both defiant against, and also, simultaneously, oppressed by brands, he tries to provide a framework for the contradictions of the brand/consumer relationship which more accurately reflect the shifting dynamics of the postmodern economy. This contradiction is summed up by Holt (2000) as follows:

As the modern branding paradigm became public knowledge, an anticultural engineering sentiment gelled that effectives cast these techniques as a threat to American ideals. A first principle of the culture of capitalism, the American variant in particular, is the primacy of the individual. Creeds against cultural engineering achieved broad resonance by demonstrating that modern branding strategies deeply contradicted this principle. While capitalism asserts that we are free to choose what we want to consume, large marketing firms seemed to be 
claiming the power to author our consumer lives through their branding. This contradiction created the space in which alternatives to cultural engineering were seeded (p.82).

This gap between how firms market their brands and how people consume is the focus of 'critical' perspectives on marketing. Holt (2000) calls this trend the 'postmodern branding paradigm' (p. 83). As consumers become aware of how they are being engineered by marketers, they increasingly resist the brand (Murray and Ozanne 1991). Faced with this mass awareness, marketers now face a contradiction: they have to hide their commercial motives in order to make money from their brands. To the extent that they fail to do so, consumers are able to peel away 'the brand veneer' (Holt 2000, p. 86) and expose the inauthenticity of conventional strategies used by brands:

When firms push aggressively at the moorings of the branding paradigm, and as consumers become more knowledgeable and reflexive about the previously accepted mechanics of branding, the conventional branding techniques developed within the culture gradually lose their efficacy (Holt, 2000, p. 80).

As consumers become more and more aware of the contradictions firms face in trying to reconcile commercial motives and non-commercial messages about self-actualization or social and political ideals, consumers will expect brands to take on a different role. As the power of the overtly manipulative brand fades, consumers will demand other functions from brands. This stage of consumer culture is what Holt (2000) calls the 'post-postmodern paradigm' (p.87)

According to him, this new 'post-postmodern' paradigm will consist in brands becoming 'cultural resources' or 'another form of expressive culture' (p.87). Consumers will form their own communities and steer clear of the 'chaotic swirl of culture' (p.87) that characterizes our world today. Brands, in this sense, can help rebel 'citizens' become the 'artists' that post-postmodern consumers want to be (Holt 2000, p. 87). They do this by becoming cultural resources which strike the consumer as being authentic rather than alienating, thus taking on the role of 'cultural specialists' which consumers can rely upon in their quest to become 'citizen-artists'. 
Holt's predictions about the post-postmodern branding paradigm, although interesting, are also disappointingly vague about what we may call the 'balance of power' between brands and consumers. On one hand, his argument appears to place the consumer as successfully countering the power of brands via the antibranding movement; on the other, it is clear that he regards brands (still) as holding residual power over consumers' imaginations which even the counter-cultural movements over the last few decades have not managed to shake off.

The questions which now confront us are, therefore: can we more accurately specify or conceptualize the relationship between brands and consumers in the post-postmodern economy? What is the nature of this relationship? In particular, what is the status of the brand today?

We can now sum up the key philosophical and sociological themes discussed so far in order to relate them to Internet technology and search engines, in particular. The relationship between postmodern consciousness and technology is almost parasitic. In the words of Venkatesh et al., (1995):

Underlying the relationship between postmodern consciousness and information technology is a profound relationship between ontology (our view of reality) and technology. One feeds on the other relentlessly. As technology creates new realities, virtual and interactive, postmodernism provides a framework within which such realities can be grasped and understood. Many of our postmodern sensibilities are concretized through technological possibilities (p. 12).

Postmodernism and virtual technologies, in fact, share profound ontological commitments: the fragmentation of attention, the multiplicity of new brand communities, the disembedding of self from localized contexts and the normative power of consumer choice. The rhetoric of Web technologists, in fact, mirror that of postmodern theorists. The kind of postmodern distanciation noted by Giddens (2005), for example, is neatly summarized by one Internet researcher in the following terms: 
Time-space compression is hyper-intensified by advances in information technologies and the digital revolution...we can now be virtually "anywhere", be virtually "anyone" and at virtually "anytime" (Thompson, 2003, p. 123).

The heterogeneity of 'selves' and the apparently unlimited choices the postmodern consumer has can now be placed in context. The next challenge for marketers, then, is to understand the unique characteristics of Search Engine Marketing (SEM) and its importance for the postmodern consumer.

\section{The ‘Search' Economy and Search Engine Marketing (SEM)}

The theoretical developments in postmodern discourse and consumer theory highlight the unique features of what is currently the fastest growing area of the Internet: Search Engine Marketing (SEM). Online searching is now the key activity of millions of consumers around the world and the sheer growth in online search volume continues unabated. According to a recent report by SEMPO (Search Engine Marketing Professional Organization), the volume of spending on SEM (Search Engine Marketing) programmes totaled over $\$ 4$ billion in 2003 and is projected to reach upwards of $\$ 7$ billion in 2007. Online search volume continues to grow at a remarkable pace, outstripping the appeal of traditional media like television, film, newspapers and the radio. Companies have to adopt leading-edge marketing strategies in order to capture their share of the 'search results' consumers see (Sen, 2005). Put simply, companies now seek to be found rather than simply being recalled, recognized or admired.

'Search marketing' may be described briefly as a system of marketing using paid or unpaid listings on web pages and other 'affiliate' sites. It has overtaken other strategies such as pop-up ads, banner ads and email marketing in popularity as the numbers of consumers using search engines grow exponentially. Keyword-banner related ads are already declining in popularity due to studies showing poor brand recall and awareness by consumers. Taking their place are paid listings using search engines. SEO (Search Engine Optimization) and Paid Placement have thus come to dominate search marketing techniques although many firms still have very little idea of how to calibrate the effectiveness of these channels. To fill this gap, companies such as SearchLatitude.com 
in the U.K. (voted last year as one of the U.K's top 5 fastest-growing companies) ensure that companies utilize SEM (Search Engine Marketing) techniques for high ROI.

The fact that all these strategies are played out in myriad and complex ways on Web pages means that branding is now subject to what Baudrillard (1998) has called 'the constraint of signification' (p. 82). In this space, signs truly refer only to other signs and all pretence at 'presence' or 'essence' or 'authenticity' is no longer necessary. Marketers who use SEM are now subject to the peculiar laws of an architecture which have barely begun to be theorized. I focus on four aspects of this new architecture of marketing and explore their implications accordingly:

Thematic spatialization. In the 'search' economy, brands gain equity from being found rather than from being contextualized, recalled or associated with desirable attributes. That is, brands are increasingly being filtered through a linguistic system associated through visual placement rather than context. Brands are no longer able to control associations and image in conventional ways. Rather, it is in how they are placed in concatenation with other signs which determines their use and power of attraction for consumers. This branding strategy exemplifies in uncanny fashion the postmodernist adage that 'the links between signs and their articulation are of major importance, for it is only through such concatenation that signs can have meaning, can signify (Lefebvre, 1991, p. 132). This phenomenon is now a science of how space signifies its own meaning.

Postmodern brand theories also shed some light on this phenomenon. One of them is the concept of associative structures (Anderson, 1983; Wyer and Srull, 1989). These structures function like memory nodes, linking semantic concepts together in the mind of the consumer (Collins and Loftus, 1975; Ratcliff and McKoon, 1989). In SEM, 'brands' have no control over how consumers 'place' nodes of association between competitors. This leads to a paradox: brands are simultaneously more and less differentiated from their competitors. Depending on how consumers decide to behave, a brand may become more or less homogenized. If consumers decide to click on ads in the editorial pages of a site instead of a 'sponsored' site, a brand may actually seem more 'different' than its nearest 
'link'. If they decide to search a 'sponsored' site, then brands are now jostling to be differentiated although they benefit from being grouped according to 'themes' of the search the consumer is performing.

Temporal hierarchization. One other distinctive feature of SEM is the 'just-in-time' feature of search engines. Brands gain equity, therefore, from being the first to be found. Moreover, in order to be found at all, brands must be found in the shortest possible time. Brands which can be found most quickly gain primacy in the minds of consumers. To be thus found, companies must rank in the best possible positions on the search results pages. Apart from making sure that they are listed on the top three search engines -Yahoo, Google and MSN - companies now invest heavily to make sure they are seen first on those sites. Adding to the confusion is the fact that these top three search engines never publicize their rankings criteria, meaning that the chances of getting to the top rankings is more an art than a science. Apart from the well-known finding that $90 \%$ users of search engines do not search beyond the third page of a listing (NielsenMedia 1997; Sullivan 2002), SEM (Search Engine Marketing) is still not well understood and has created a niche for SEM companies to act on behalf of their clients. The need to be temporally configured to maximize search positioning has resulted in a thick layer of intermediation between the brand and the consumer. Brands find themselves increasingly 'coded' to criteria of space and time which are mediated by a 'third economy' of time and space constraints operating, paradoxically, in the seemingly limitless horizon of cyberspace. Consumers intuit the control and freedom of this idealized space and act accordingly.

Consumer promiscuity. Brands, according to Holt (2000), have tended to rely on distracting the consumer from its real (commercial) motivations by 'promiscuously stitch(ing) stories and images to their brands that may have nothing to do with the brands' real history and consumption' (p. 84). In the 'search' economy, the roles are reversed. It is now consumers, rather than marketers, who switch 'stories' promiscuously between brands to fulfil their 'search'. Brands need to leverage on, rather than being defeated by, consumer promiscuity. The result is more diffuse -- more organic -- than the easily identifiable counter-cultural movements described earlier by marketing critics. One 
example is the hugely successful MySpace.com site which, according to its founder, Chris DeWolfe, signals a generation rejecting the "segmented and narrow" choices of traditional media and used to selecting from thousands of songs on their iPod, hundreds of cable channels or millions of websites (The Observer, 18 June 2006). It is now harder than ever for companies to segment or target markets. In order to capture as many consumers as possible, companies have to make new acquisitions. When Rupert Murdoch’s News Corp paid £332.85m for MySpace’s parent company Intermix Media last July, it puzzled many media-watchers. Now it is widely admitted that he made a canny move, capturing millions of users in a way he could never have otherwise.

Consumers as Brand-Creators. Since consumers now create brand awareness by performing millions of random searches accordingly to criteria which even 'experts' disagree on, they are single-handedly creating brands. Without their doing much about or with their 'brand,' the Arctic Monkeys rose to fame after fans used MySpace to spread the word about it and search volumes surged afterwards.

In a move to imitate this model, anyone looking to develop a brand can build up similar fanbases in the hope that, left to their own devices, fans create interest around the brand in sufficient volume that another bigger brand will come along and either merge with, or acquire, it. In this account, consumers are neither emancipated nor active co-designers of their 'identities,' nor are they actively filtering out brands which do not satisfy their taste for cultural authenticity. Instead, they are coming together as a result of common tastes and interests across a wide spectrum of activities and the rules of the game - legal, moral and social - are still being played out.

To sum up: the implications of the 'search' economy for the dynamic of the brandconsumer relationship are significantly different from both the postmodern and the postpostmodern models. According to the postmodern paradigm, consumers react to the contradictions between brands' espoused ideals and the techniques they used to convey those ideals. As consumers became more and more aware of these contradictions, brands came to lose their cachet or prestige. Postmodern consumers are skeptical of brands which try to 'look' authentic by using images which are removed from their crassly commercial motivations. Every terrain, it seems, is now tainted by corporate 
sponsorship, from the heights of Everest to a starving child in an Indian village. No medium today, from film to $\mathrm{CDs}$ to radio, can appear pristine to the postmodern consumer.

The post-postmodern consumer, according to Holt (2000) will want to view brands as cultural resources which they can use to authenticate themselves as citizens. Such consumers will pick and choose among brands like bricoleurs (the French description for one who picks and chooses from heterogeneous materials), filtering out those which are they can use as means to express their cultural identities. Others will choose to stay on the fringes and steer clear of consumer culture. They will form their own enclaves and identify themselves not through brands but through personal values, beliefs, work, art and so on.

The latest stage in the marketing movement - what I call the 'search' economy -- signals a radical departure from these branding paradigms. The consumer is the seeker of products and services; brands simply seek to be found by as many consumers in as brief a time as possible. In this new economy, the consumer does not discriminate between brands so much he or she accumulates online experiences of people and things which will satisfy a plethora of tastes and desires throughout the day and night. The 'brand' is what is able to be found first. It is important to note that SEM tends to erode brand-loyal or brand-seeking behaviour, in any case. It has been shown in studies, for example, that consumers are more likely to click on links which contain the exact phrase they are searching for and will ignore brand names or even special offers if they come up on that link (www.thereadingroom.com). Firms now struggle not to differentiate themselves but to be seen in the same spaces as the most highly-ranked sites. In other words, brands are increasingly coming to understand that homogenization coupled with personalization (rather than naïve notions of 'product differentiation') is the new denominator of success. Successful brands in the digital economy are increasingly reliant on extensive, often highly expensive, consumer research of online buying behaviour; as a result, SEM is a rapidly evolving landscape in which winners cannot be confidently predicted. In this new economy, firms which are able to manipulate and utilize title tags, meta-tags, headings 
and other links in line with sophisticated surveillance-based research may tend to have an advantage.

The 'search' economy may well be the last frontier for consumers seeking a pristine experience. The proof of this is the fact that millions of search engine users today shape the destinies of brands before the latter are even born. Marketers, in this sense, have completely given over ownership of brands to the consumers who create them. Instead of reacting to brands (as both the postmodern and post-postmodern paradigms ultimately imply), the consumer will create them. The de-coupling of the link between marketer and brand is clearly already a fait accompli, as the case of sites like MySpace, YouTube, Geocities and Friendster show. The communities on these sites are arguably the most avid and powerful consumers the world has ever seen, a phenomenon made possible by the 'search' economy.

\section{Conclusions and Managerial Implications}

This paper began with a brief discussion of the link between postmodernity and the implications of technology for conceptions of the self. The discussion of one of the newest phenomena to emerge in the online space focuses these debates in a very real way for marketers and brand researchers.

My paper extends current thinking on how postmodern consumers make brand choices. The 'search' economy forces a fundamental rethink of conventional branding wisdom. For one thing, search engine marketing problematizes, and perhaps even overturns, the conventional wisdom among brand managers and marketers that brand-building takes time and "necessitates a longer term commitment" (de Chernatony and Riley, 1998, p. 437) to consumers' values. This kind of concern with 'values' shows just how different the rules are for SEM marketers trying to build online brands, if indeed there are rules to follow. The Web is evolving too rapidly to allow for brand-building on 'modernist' or even 'postmodernist' time - as global brands come under increasing scrutiny and suspicion, it is likely that much more targeted and smaller brands premised on specific brand promises emerge as winners in the 'search' economy. These brands may not own websites as such: they simply attach themselves to relevant links which have been carefully chosen to reflect specific values for a specific length of time. Thus, brands may 
be 'displayed' and then 'taken down', like seasonal collections of fashion or foods through virtual displays on social sites. They attach themselves to the most 'searched' sites and banner displays rather than what most marketers today still like to call the most 'valued' customers. I call this 'viral branding' and this trend will no doubt spawn new valuation methodologies to add to what is already occurring in this space.

Brand managers will also have to be much more careful about the proliferation of 'unintended' brand associations. In 'modern' economies, brands would be identified with products or services of one kind or another but the 'postmodern' fragmentation of consumers' identities and agglomeration of new brand identities combine to generate almost uncontrollable sets of myriad associations with the simplest of search terms. Brand managers now need to decide on the possible parameters and applications of the services they offer, which can be an extraordinarily difficult and risky process. The word 'menu', for instance, means vastly different things to a restaurateur than to a graphic designer or software developer. The former automatically assigns 'food choices' to the search term while technical specialists may simply be searching for 'desktop' menus. In another example, a well-known cleaning company could not understand why their chosen google adword 'bleach' failed to target households and housewives and instead attracted thousands of teenagers. After lengthy investigations undertaken in consultation with their interactive marketing agency, it was discovered that 'Bleach' was in fact the name of a famous Japanese 'Manga' cartoon watched by thousands of Japanese schoolchildren!

The managerial implications of these insights are far-reaching. Marketers must develop at least a rudimentary understanding of search engines, their algorithms, keyword selection criteria and ranking philosophies. The brand positioning of a company must be based on new knowledge of this kind and it is important that such knowledge be cascaded down through the organization. Thus, market research takes on a new importance in the search economy. Ironically enough in Western information-rich societies, finding out what the consumer wants' becomes increasingly difficult as customers take up, and then shed, their identities at will and at increasingly shorter intervals. In effect, the customer is not one, but many-in-one. For marketers, the implications are likely to involve radically new strategies in planning and measurement. Some of these include, firstly, developing 
new indices and methods of accounting for brand 'optimization' instead of 'equity'; secondly, reconceptualizing the relationship between 'brand' and 'consumer(s)' and, thirdly, establishing an integrated understanding of the 'search' economy supply chain -from consumers to intermediaries such as search engine optimizers to brand entrepreneurs and search analysts.

Furthermore, marketers will need to rely increasingly on an array of specialists in 'search' to stay ahead of the curve. Managerially, they will need to master, either by themselves or collaboratively, a range of technical skills to support their strategic visions. The deciphering of online brand associations and all the cognitive and semantic links they entail are skills which are still fairly alien to brand managers at the moment. A new breed of interactive marketer and online brand specialist should become more common over the next few years as SEM continues its explosive growth. In future, strategic branding decisions may be led by online specialists rather than the other way around. This development would hardly be surprising, considering the increasing spend by companies on online 'search' advertising and marketing.

Search engines also signal a key change for advertising activities which used to rely on images to interact with customers. Companies which are used to investing heavily in images and graphics as a good way to bond with their customers will find that in SEM, 'Copy is King'. In a crowded and expensive space, words are incredibly important to generate interactive experiences for consumers in seconds before they are distracted by competitive words or phrases. The extremely short attention spans of online consumers will increasingly put pressure on marketers to devise ever more parsimonious, yet effective, advertising copy on search engines.

Last, but not least, the implications of SEM for competitor and business intelligence are also important to marketers. Specifically, SEM allows far more accurate measurement of the effectiveness of advertising and marketing campaigns when compared to traditional media. The conventional goal of marketers to achieve an "organization-wide business intelligence pertaining to current and future customer needs" (Kohli and Jaworski, 1990) may be a fine idea in principle, but is notoriously difficult for marketers to achieve. By 
contrast, SEM puts a great deal of power in the hands of skilled SEM marketers who can, for instance, precisely measure the effects of pay-per-click advertising in order to guide bidding and buying decisions on behalf of the company.

Although I have aimed to integrate hitherto disparate streams of literature into the analysis of SEM, my analysis, of course, has its limitations. I have not examined in detail, for example, the various consumer segments which actively utilize search engines. Future research may focus on identifying these groups in order to specify their search behaviours and fine-tune advertising campaigns targeted at them. Moreover, the role of other intraorganizational and extraorganizational stakeholders in optimizing the capabilities of search engines has not been covered. Marketers today work with many stakeholders to achieve results and their impact on SEM campaigns cannot be underestimated.

\section{Conclusion}

Today's 'search' economy is increasingly encroaching upon every aspect of our lives. Virtually every generation is touched by its reach and power. Even the residual power that brands may have had in postmodern and post-postmodern accounts of marketing is fast being eroded by the specific characteristics of this new economy.

Accounts of 'consumer resistance' against the deceit which brands are accused of practising belong, in this account, to another era. Although accounts like Holt's (2000) give credence to an image of the consumer as liberated (postmodern) and a 'citizen-artist' (post-postmodern) involved in co-creating his or her identity with brands, the latest development in this discourse must include the seismic changes occurring online. Consumers may, at this moment in history, be capable of mounting a real resistance to brands but in wholly unexpected ways.

This paper has examined one of the most prominent manifestations of this new economy - the 'search' paradigm -- but it is evolving rapidly and takes many forms. As search engines move to mobile platforms and as revenue streams and partnerships across multiple channels proliferate, consumers will likely shift the branding dynamic yet again. 
Ultimately, perhaps, is as the founder of MySpace, puts it, the new economy's brands are in the hands of users:

They're defining the experience, not us. We're just letting it rip. What I'm basically trying to say is that as long as we don't screw it up, we'll be fine. 


\section{References}

Aaker, D. A., Biel, A. (Eds.) (1992), Building Strong Brands. Lawrence Erlbaum Associates, Hillsdale, N.J.

Ahuvia, A.C. (2005), "Beyond the Extended Self: Loved Objects and Consumers' Identity Narratives”, Journal of Consumer Research, Vol. 32, pp. 171-184.

Anderson, J. R. (1983), The Architecture of Cognition. Harvard University Press, Cambridge, MA.

Baudrillard, J. (1998), The Consumer Society: Myths and Structures, C. Turner (trans.), London: Sage Publications.

Bauman, Z. (1997), Postmodernity and its Discontents, Blackwell: Polity Press.

Beck, U. (2006), Cosmopolitan Vision. Blackwell: Polity Press.

Belk, R.W. (1988), "Possessions and the Extended Self", Journal of Consumer Research, Vol. 15, No. 2, pp. 139-68.

Carroll, B.A. and Ahuvia, A. C. (2006), "Some Antecedents and Outcomes of Brand Love", Marketing Letters, Vol. 17, pp. 79-89.

Collins, A.M., Loftus, E.F. (1975), “A Spreading-activation Theory of Semantic Processing”, Psychological Review, Vol. 82 No. 6, pp. 407-428.

De Chernatony, L. and Riley, F. D. (1998), "Defining a Brand: Beyond the Literature with Experts' Interpretations", Journal of Marketing Management, Vol. 14, pp. 417443.

Dholakia, U.M. and Rego, L.L. (1998), "What makes commercial Web pages popular? An empirical investigation of Web page effectiveness", European Journal of Marketing, Vol. 32 No.7/8, pp. 724-736.

Firat, A.F. and Schultz, C.J. II (1997) "From Segmentation to Fragmentation: Markets and Marketing Strategy in the Postmodern Era", European Journal of Marketing, Vol. 31, No. 3-4, pp. 183-207.

Firat, A. F., Venkatesh, A. (1995), "Liberatory Postmodernism and the Reenchantment of Consumption," Journal of Consumer Research, Vol. 22 (December), pp. 239-267.

Giddens, A. (1990), The Consequences of Modernity, Blackwell: Polity Press.

Holt, D.B. (2002), "Why do Brands Cause Trouble? A Dialectical Theory of Consumer Culture and Branding", Journal of Consumer Research, Vol. 29 (June), pp. 70-90. 
Katz, H. (1991), "How Major U.S. Advertising Agencies are Coping with Data Overload", Journal of Advertising Research, Vol. 31, (Feb/Mar), Issue 1, pp. 7-16.

Kling, A. (1994), "The economic consequences of the World Wide Web", Paper presented at the Second World Wide Web Conference: Mosaic and the Web, Geneva, Switzerland.

Lasch, C. (1985), The Minimal Self, London: Picador.

Lasch, C. (1977), Haven in a Heartless World, New York: Basic Books.

Lefebvre, H. (1991), The Production of Space (trans. D. Nicholson-Smith), Blackwell, Oxford.

Lindstrom, M. (2001), Clicks, Bricks, and Brands, Kogan Page.

Lyotard, J. (1985), The Postmodern Condition, Minneapolis: University of Minnesota Press.

McLaughlin, M.L. (1996), “The Art Site on the World Wide Web”, Journal of Communication, Vol. 46 No. 1, pp.51-79.

Nielsenmedia. (1997), Search engines most popular method of surfing the Web. Accessed on: 30 August 2000 at: http://www.commerce.net/news/press/0416.html.

Ozanne, J., Murray, J. (1995), "Uniting Critical Theory and Public Policy to Create the Reflexively Defiant Consumer”, American Behavioural Scientist, Vol. 38 (February), pp.516-525.

Ratcliffe, R., and McKoon, G. (1988), "Similarity Information versus Relational Information", Cognitive Psychology, Vol. 21, pp.139-155.

Sen, R. (2005), “Optimal Search Engine Marketing Strategy”, International Journal of Electronic Commerce, Vol. 10 No. 1, pp. 9-25.

Slevin, J. (2000), The Internet and Society, Cambridge: Polity Press.

Srivastava, R., Shocker, A.D. (1991), "Brand Equity: A Perspective on Its Meaning and Measurement", Working paper, Graduate School of Business, University of Texas at Austin.

Sullivan, D. (2005), “The Mixed Message of Paid Inclusion”, Search Engine Report, May 6, available at http://searchenginewatch.com/sereport/02/05_inclusion.html.

Sullivan, D. (2002), "Search Engine Math", available at http://www.searchenginewatch.com/facts/article.php/2156021. 
Tauber, E. M. (1988), "Brand Leverage: Strategy for Growth in a Cost Controlled World", Journal of Advertising Research, Vol. 28 (August/September), pp. 26-30.

Thompson, C.J. (2003), Postmodern consumer goals made easy!!!!. In: S. Ratneshwar, D.G. Mick and C. Huffman (eds.), The Why of Consumption: Contemporary Perspectives on Consumer Motives, Goals, and Desires, London, New York: Routledge, pp. 120-139.

Thompson, C. J. and Troester, M. (2002), "Consumer Value Systems in the Age of Postmodern Fragmentation: The Case of the Natural Health Microculture", Journal of Consumer Research, (March), Vol. 28, Issue 4, pp. 550-571.

Venkatesh, A., Dholakia, R.R.and Dholakia, N. (1995), "New Visions of Information Technology and Postmodernism: Implications for Advertising and Marketing Communications", Walter Brenner and Lutz Kolbe (eds.), The Information Superhighway and Private Households: Case Studies of Business Impacts, pp. 319325.

Wyer, R. S., Jr., Srull, T.K. (1989), "Person Memory and Judgment”, Psychological Review, Vol. 96 No.1, pp. 58-83. 